\title{
Physics Teacher-Leaders' Learning in a National Program of Regional Professional Learning Communities
}

\author{
Smadar Levy, Esther Bagno, Hana Berger, and Bat-Sheva Eylon \\ The Science Teaching Department, Weizmann Institute of Science, Rehovot 7610001, Israel
}

\begin{abstract}
We studied the learning of high-school physics teacher-leaders in a national Professional Learning Communities (PLCs) program that operates using a "Fan Model": the teacher-leaders' PLC is led by a team from the Weizmann Institute of Science, while they simultaneously lead regional PLCs of physics teachers all over Israel. The learning sequence of one learner-centered activity was chosen as the context for this study. We developed a theoretical framework: Physics Knowledge for Teaching and Leading (PKTL), which we used for a micro-level discourse analysis, together with the Knowledge Integration (KI) perspective. The results show that the evidence-based learning of a new learner-centered activity fostered the learning of physics and a rich array of other aspects of teacher-leaders' knowledge. The teacher-leaders' PLC turned out to be a meaningful, supportive, and enriching learning environment. We suggest that our program can serve as an effective model for the professional development of both teacher-leaders and teachers in regional PLCs.
\end{abstract}

\section{INTRODUCTION}

This study examined the learning of high-school physics teacher-leaders that participated in a national Professional Development (PD) program of Professional Learning Communities (PLCs). The main objectives of the program are to enable physics teachers to examine collaboratively their teaching as well as their students' learning [1-2], to address the challenges of teaching physics [3-5], to develop physics teacher-leaders [6-9], and to promote learnercentered teaching. The learner-centered strategies in the program are research based, and are aimed to develop and enhance students' conceptual understanding and to promote collaborative learning and ownership of learning physics.

The program operates by using a "Fan Model" (described in Fig.1): the teacher-leaders participate in a PLC led by a team from the Science Teaching Department at the Weizmann Institute of Science, while the teacherleaders simultaneously lead regional PLCs of high-school physics teachers all over Israel.

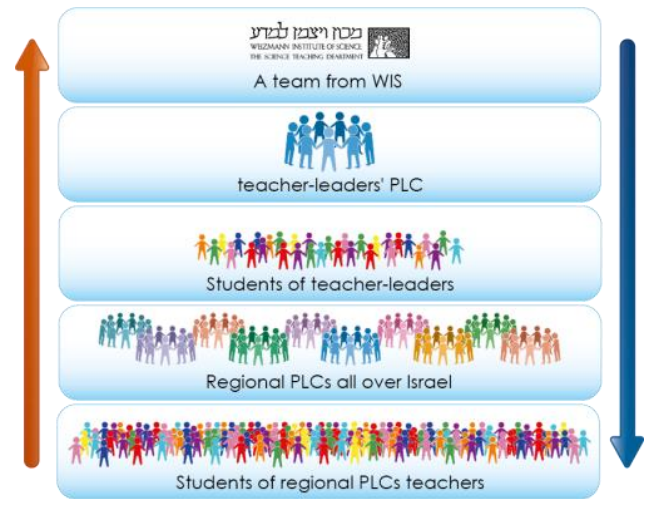

FIG 1. The "Fan Model" used in the physics teachers' PLCs program
The program is based on teacher-leaders' active experiences in all contexts of their work: as learners at teacher-leaders' meetings, as high-school physics teachers, and as leaders of regional PLCs. The teacher-leaders' learning is evidence based [10]: They try the new teaching strategies, collect and analyze data about the learning of students and teachers in the regional PLC, as well as collaboratively reflect on the evidence from classes and from the regional PLCs regarding learning, teaching, and the leading of PLCs.

The program has operated since 2012. Currently there are 25 teacher-leaders and 11 regional PLCs with about 200 high-school physics teachers (about 20\% of all high-school physics teachers in Israel), teaching approximately 15,000 students. Each PLC, including both the teacher-leaders' PLC and regional PLCs, operates by face-to-face meetings lasting 4 hours each, twice a month during the school year, totaling 60 hours per year.

We studied the teacher-leaders' learning in the context of one learner-centered activity. Our main research question is: what aspects of the teacher-leaders' knowledge were evidenced by the learning of a new learner-centered activity in the PLCs program? The results enhance our understanding of the teacher-leaders' learning and how the program promoted it, and can contribute to the design of effective PD programs for both teachers and teacherleaders.

\section{THEORETICAL FRAMEWORKS}

In order to characterize the knowledge that physics teacher-leaders need as teachers and as PLC leaders, we developed the Physics Knowledge for Teaching and Leading (PKTL) framework (see Fig. 2), an elaboration of Mathematical Knowledge for Teaching (MKT) [11]. 


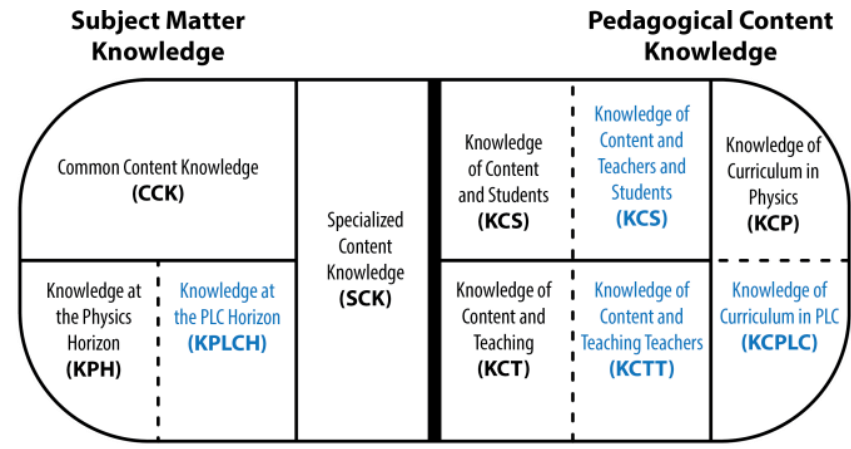

FIG 2. The Physics Knowledge for Teaching and Leading (PKTL) framework for characterizing the knowledge of physics teacherleaders in a PLCs program.

Aspects of MKT that were adapted from mathematics to physics appear in Fig. 2 in black. We added the knowledge aspects in blue in order to suit the context of teacher-leaders in a PLCs program. The physics teacher-leaders' Subject Matter Knowledge and their Pedagogical Content Knowledge [12] were subdivided, as presented in Fig. 2. Examples that will clarify the various aspects of teacherleaders' knowledge will be presented later.

We also used the Knowledge Integration (KI) perspective [13] to study the teacher-leaders' learning. According to KI, learners build knowledge by undergoing four processes: 1) Eliciting ideas: learners become aware of their pre-existing knowledge; 2) Adding ideas: learners are introduced to new ideas; 3 ) Developing criteria to evaluate ideas: questions and tests that the learners use to evaluate whether they consider the ideas as acceptable; 4) Sorting out and reflecting: the learners reflect on and differentiate between their pre-existing ideas and the newly acquired ones based on specific criteria, e.g., scientific principles. The four processes do not necessarily appear in the described order.

\section{METHODOLOGY}

\section{A. The participants}

All the teacher-leaders in the program are experienced high-school physics teachers who joined the teacherleaders' PLC in different years, and lead (in pairs) a regional PLC of high-school physics teachers. Most of them had no previous experience as teacher-leaders. Twenty teacher-leaders participated in the meetings that dealt with the activity chosen for this study.

\section{B. The activity: 'Interpretation of a Formula'}

The 'Interpretation of a Formula' is a research-based classroom activity [14] that was chosen as the context for this study, as a representative of other learner-centered strategies in the PLCs program. The activity encourages the students to describe explicitly the components of a chosen formula, its units, and the conditions under which the formula can be applied. The students are required to represent the relationships between the components of the formula in multiple ways, to identify special cases of the formula, and to explain, in their own words, the physical meaning of the formula in these cases.

The activity takes 1-2 lessons to complete and consists of a four-phase cycle, based on the KI processes: 1) Individual work, in which the students, guided by a set of tasks, explicitly elicit their knowledge about the formula; 2) Group work, in which the students work in small groups, on the same set of tasks, evaluate their individual work, add new ideas, and reach a consensus (or a disagreement); 3) A plenary discussion, in which a representative of each group presents the group's consensus, all the issues raised in the group work are discussed, and a classroom summary is formulated; 4) Individual reflection, in which each student individually accounts for what he or she has learned and identifies what still remains unclear.

\section{The learning sequence of the 'Interpretation of a Formula' activity in the teacher-leaders' PLC}

The 'Interpretation of a Formula' activity was new to all the teacher-leaders. It was administered in a sequence of four teacher-leaders' PLC meetings (lasting about two months during the 2015 school year) and included enactments in the teacher-leaders' classrooms and in the regional PLCs. Each of the meetings included the KI-based four-phase cycle of individual work, group work, a plenary discussion, and reflection.

In the first meeting the teacher-leaders experienced the activity as learners with the formula: $x=x_{0}+v_{0} t+\frac{1}{2} a t^{2}$. Then they enacted the activity in their classes, collected students' papers, and in the second teacher-leaders' meeting they collaboratively analyzed them, identified students' difficulties, and reflected on their experiences. In the third meeting, the teacher-leaders experienced the activity again, with the formula: $V=\varepsilon-I r$. Then they enacted the activity in their regional PLC, where the teachers underwent a similar learning sequence with the formula: $x=x_{0}+v_{0} t+\frac{1}{2} a t^{2}$, including collaborative analysis of students' papers. In the fourth meeting, the teacher-leaders reflected on their experiences in the regional PLCs.

\section{Data Sources}

All four teacher-leaders' meetings were audio recorded and videotaped, and later transcribed and analyzed.

\section{E. Data Analysis}

We used a micro-level discourse analysis to study the teacher-leaders' learning. In each of the four teacher-leaders' 
meetings (totaling 16 hours), we focused on the plenary discussion, which also explicitly articulated previous learning by the individuals and the small groups. From the KI processes, we focused on "adding ideas", which provided rich data on learning in all four meetings. The plenary discussions were segmented into utterances, which were coded according to the relevant aspect of knowledge in the PKTL framework (using Atlas.ti software). All four meetings' discourses were analyzed independently by the four co-authors, compared, and discussed until we reached an agreement of about $90 \%$. Then the results were discussed with two other researchers.

\section{RESULTS}

The teacher-leaders' learning of the 'Interpretation of a Formula' activity was characterized by the aspects of knowledge that were fostered in each meeting. This also enabled us to examine which 'hat' the teacher-leaders 'wore' in each meeting, out of their three 'hats': the hat of learners, the hat of physics teachers, and the hat of PLCs leaders.

Most of the teacher-leaders were deeply engaged in the meetings and actively participated in the plenary discussions, as shown in Table 1 .

The aspects of knowledge that were expressed during the plenary discussions in each of the four teacher-leaders' PLC meetings, according to the PKTL framework, are presented in Fig. 3. Different aspects of knowledge predominated in each of the meetings, as denoted by the different colors.

In the initial meeting the teacher-leaders first experienced the 'Interpretation of a Formula' activity as learners; it stimulated them to articulate ideas in physics that are related to Common Content Knowledge (CCK), and even more ideas that are related to Specialized Content Knowledge (SCK). CCK is defined as knowledge in physics that can be used in any context, not necessarily teaching, e.g., " $t$ is the time elapsed since we started to measure" (Shira). SCK is the knowledge in physics that is special for teachers, but does not yet require teachers' knowledge of students or knowledge of teaching, e.g., "The position is defined relative to the origin of the selected $x$ coordinate line" (Danny). The differentiation between CCK and SCK can sometimes be subtle, and in these cases the categorization was made according to the criterion of how common is the use of this idea/concept/representation among physicists versus physics teachers. However, both CCK and SCK constitute knowledge in physics.

TABLE I. The number of participants, speakers, and utterances (KI - adding ideas) during the plenary discussions in each meeting

\begin{tabular}{lcccc}
\hline \hline & Meeting 1 & Meeting 2 & Meeting 3 & Meeting 4 \\
\hline Participants & 19 & 20 & 20 & 20 \\
Speakers & 14 & 14 & 14 & 13 \\
Utterances & 42 & 39 & 21 & 29 \\
\hline \hline
\end{tabular}

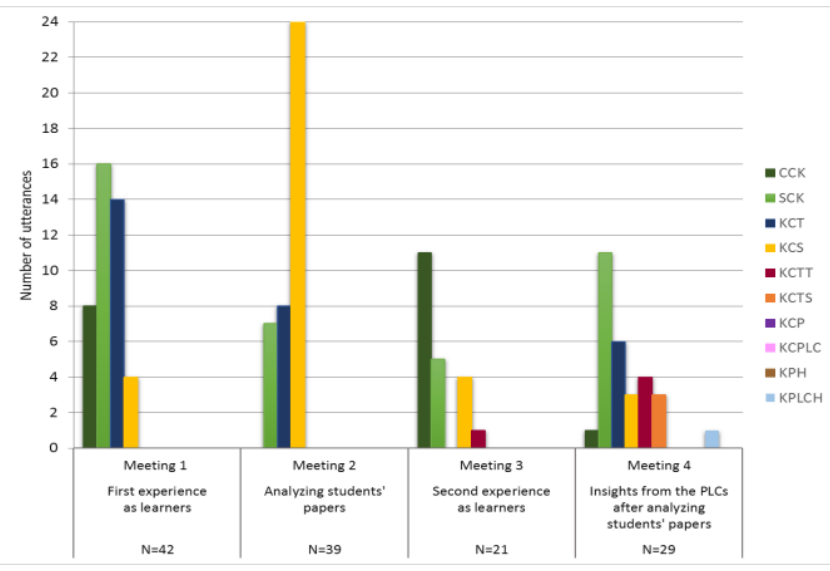

FIG 3. The aspects of knowledge, according to the PKTL framework, which were expressed during the plenary discussions in each meeting.

Other ideas that were discussed in this meeting are related to Knowledge of Content and Teaching (KCT), e.g., "We have to tell the students in advance that these are SI units" (Reut). There were also some references to Knowledge of Content and Students (KCS), e.g., "I guess that some students will write that if the units on the left are $m+m+m$, then the units on the right are $3 m^{\prime \prime}$ (Roy).

In the next meeting the teacher-leaders collaboratively analyzed their students' papers, and therefore were mainly engaged in Knowledge of Content and Students (KCS), as well as Knowledge of Content and Teaching (KCT) and knowledge in physics (SCK).

In the third meeting the teacher-leaders experienced the activity as learners again, with the formula: $V=\varepsilon-I r$, which resulted in ideas that are related to knowledge in physics (both CCK and SCK) and Knowledge of Content and Students (KCS). For the first time, towards the enactment of the activity in the regional PLCs, the teacher-leaders expressed ideas that are related to Knowledge of Content and Teaching Teachers (KCTT).

In the last meeting the teacher-leaders shared insights from the regional PLCs, after analyzing students' papers, and for the first time they were engaged in aspects of knowledge that are specific to their role as PLC teacherleaders: 1) Knowledge of Content and Teaching Teachers (KCTT), e.g., "We should give the teachers enough time to experience the activity as learners because they are not familiar with this approach" (Roy); 2) Knowledge of Content and Teachers as Students (KCTS), e.g., "If the teachers will not enact this activity in class right away and become convinced that the effort is worthwhile, they will probably forget about it and will never use it again" (Sofia); 3) Knowledge at the PLC Horizon (KPLCH), e.g., "In the PLC meetings we always have to follow all phases of such activities in order to make it a habit, so that the teachers will do the same in their classes " (Danny).

Even though it was the third time that the teacherleaders discussed this formula, the collaborative reflection 
during this meeting, after the analysis of students' papers in the regional PLCs, stimulated a deep exploration into its origins. Teachers in one of the regional PLCs claimed that students who wrote that $1 / 2$ is a component of the formula $x=x_{0}+v_{0} t+\frac{1}{2} a t^{2}$ were wrong. This stimulated a profound discussion between the teacher-leaders regarding the origins of the half in this formula and the meaning of numerical coefficients in physics formulae in general, including the physics-mathematics interplay.

An analysis of Fig. 3 reveals that different aspects of knowledge were predominant in each meeting, and that most aspects of teacher-leaders' knowledge were fostered in the learning sequence as a whole. However, some aspects of teacher-leaders' knowledge did not emerge from the data, e.g., Knowledge of Curriculum in Physics (KCP), defined as knowledge of the physics curriculum for each class in school, and Knowledge of Curriculum in the PLCs (KCPLC), defined as knowledge of the planned content for the PLCs meetings.

The teacher-leaders 'wear three hats': the hat of learners, the hat of physics teachers, and the hat of PLCs leaders. The dominant hats in the first three meetings were those of learners and teachers, and they 'wore' them simultaneously. It took more time for them to 'put on' the hat of PLC leaders.

\section{DISCUSSION AND CONCLUSIONS}

The teacher-leaders' learning is based on their active experience as learners at teacher-leaders' PLC meetings, as high-school physics teachers, and as regional PLCs leaders. The alternating meetings, every other week, of the teacherleaders' PLC and the regional PLCs helped to integrate the teacher-leaders' learning into their practice, both as teachers and as teacher-leaders.

The case of the 'Interpretation of a Formula' activity is a typical example of a learning sequence in the program.
Similar learning sequences have been applied in a variety of research-based and learner-centered strategies during the seven years of the program.

The micro analysis of the discourse in the teacherleaders' PLC, using the PKTL framework together with the KI perspective, enabled us to characterize the teacherleaders' learning and the rich array of their knowledge. The learning of the new teaching activity fostered the learning of physics and most of the other aspects of teacher-leaders' knowledge, and stimulated discussions about many aspects of teaching and learning.

The evidence-based approach encouraged the teacherleaders' to accept new ideas, and motivated them to implement changes in their practice. In a survey conducted among the students of the PLCs teachers ( $N=737$ students) in May 2016 (towards the end of the following school year), about $70 \%$ of the students reported that the 'Interpretation of a Formula' activity was used in their physics lessons more than twice that year. These findings indicate that the teacher-leaders not only changed their knowledge and their practice, they also succeeded in leading the teachers in the regional PLCs to make similar changes.

The teacher-leaders' PLC turned out to be a meaningful, supportive, and enriching learning environment, in which the teacher-leaders shared ongoing PD with their peers, who underwent similar experiences.

The "Fan Model" in the program serves as an effective model for promoting the learning of both the teacherleaders and the teachers in the regional PLCs, and demonstrates the feasibility of a sustainable PD program [15] in which multiple facilitators (the teacher-leaders) enact a PD program in multiple settings (the regional PLCs).

Having a better understanding of the learning processes of physics teacher-leaders can contribute to the design of effective PD programs for both teachers and teacherleaders.
[1] V. Vescio, D. Ross, and A. Adams, Teach. Teach. Educ. 24, 80 (2008).

[2] B.S. Eylon and E. Bagno, Phys. Rev. Phys. Educ. Res. 2, 020106 (2006).

[3] A. Madsen, S. B. McKagan, and E. C. Sayre, Phys. Rev. Phys. Educ. Res. 11, 010115 (2015).

[4] The National Academies. Science Teachers Learning: Enhancing Opportunities, Creating Supportive Contexts. (National Academies Press, Washington, DC, 2015).

[5] E. Etkina, B. Gregorcic, and S. Vokos, Phys. Rev. Phys. Educ. Res. 13, 010107 (2017).

[6] B. A. Criswell, G. T. Rushton, S. P. McDonald, and T. Gul, Res. Sci. Edu. 1 (2017).

[7] H. Borko, K. Koellner, and J. Jacobs, J. Math.Behav, 33, 149 (2014).
[8] M. Klentschy, Sci. Educator, 17, 57 (2008).

[9] B. Lewthwaite, Sci. Educ. 90, 331 (2006).

[10] B. S. Eylon, H. Berger, and E. Bagno, Int. J. of Sci. Ed. 30, 619 (2008).

[11] D. L. Ball, M. H. Thames, and G. Phelps, J. Teach. Educ. 59, 389 (2008).

[12] L. S. Shulman, (1987). Harvard Educ. Rev. 57, 1 (1987).

[13] M. C. Linn and B.S. Eylon, Science learning and instruction: Taking advantage of technology to promote knowledge integration (Routledge, 2011).

[14] E. Bagno, H. Berger, and B. S. Eylon, Phys. Educ. 43, 75 (2008).

[15] H. Borko, Educ. researcher, 33, 3 (2004). 